\title{
Emotional Labour and Deviant Workplace Behaviour among Health Workers
}

\author{
Clement Osigwe OKHAKHU, ${ }^{1}$ \\ Simon Ayo ADEKUNLE ${ }^{*}$ \\ ${ }^{1}$ Department of Business Administration and Management, \\ Auchi Polytechnic, Auchi, Edo State \\ E-mail: okhakhuclement@auchipoly.edu.ng \\ ${ }^{2}$ Department of Business Administration, \\ Faculty of Management Sciences, \\ University of Benin, Benin City \\ *Corresponding e-mail: adeksim@yahoo.com
}

\begin{abstract}
This paper investigates the influence of emotional labour on deviant workplace behaviour (DWB) among health workers in teaching hospitals. The data used have been collected from health workers in two government-owned teaching hospitals through a survey research design and have been analysed using descriptive and inferential statistics. The paper finds that superficial acting and deep acting are positively related to deviant workplace behaviour among health workers in teaching hospitals, and honest acting has negative but significant contributions to deviant workplace behaviour. The paper concludes that in order for teaching hospitals to achieve person-job fit, health workers in training should be exposed to the reality that they would be required to master their emotions to succeed in their practice. It is therefore recommended that the management of teaching hospitals as well as government organizations should ensure that rules and policies are enforced to curb certain deviant behaviours, which could otherwise easily become norms if taken for granted.
\end{abstract}

Keywords: deviance, emotions, health workers, hospitals, workplace JEL Classification: D2, D23

\section{Introduction}

It is common knowledge that emotions that people show have a lot to do with the kind of interactions that happen between them (Iyayi, 2011). Emotions in the workplace are no longer seen as private issues as any emotional display of an employee is regarded as a "public performance". Whatever happens in the 
organization happens in the public and becomes part of a social context created together by employees and customers. It is therefore pertinent to explore how emotions are managed in the workplace to improve work outcomes. What is next is to determine how organizations and their employees manage this integral part of organizational life to achieve effectiveness. Lazanyi (2010) posited that in a bid to put their employees on the right track, work organizations would develop directives and disseminate myths and stories or compel them to produce the desired emotional displays. The outcome of this emotion management is referred to as emotional labour. Three strategies for performing emotional labour have been identified and documented in the literature: superficial acting, in which employees simulate and display certain emotions as different from the emotions they feel: "by changing their outward appearances, facial experience, voice tone, or gestures, when exhibiting required emotions" (Chu, 2002: 18); further, there is deep acting, in which "employees influence what they feel in order to express the reaction they are required to display" (Virk and Malhotra, 2016: 164), and honest acting, which is the natural emotional response to a particular circumstance that meets the emotional demands of the organization (Lazanyi, 2010). Our concern is to explore how emotion management impacts employees' work outcomes. As noted earlier, organizations and their employees manage emotions as an important strategy to achieve organizational effectiveness. However, achieving effectiveness is not always the case as efforts put into managing feelings often lead to and predispose the actors to dysfunctional behaviours in the workplace. In this study, this range of behaviours is called deviant workplace behaviour (Robinson and Bennett, 1995).

Deviant workplace behaviour is a common problem in today's organizations. It is common knowledge that organizations in the current economy face many obstacles in their bid to achieve a competitive advantage. What may not be well-known is the threat to the success of the organization posed by the very people who make up the organization. Hussain (2015) observed that organizations bring together different employees, who aspire for a common goal as they work in a group. This groupwork provides a platform for interaction and the display of a variety of behaviours. According to Hussain (2015: 1), "sometimes the impacts of these behaviours leave a positive effect on others' wellbeing and sometimes they harm in a manner that [the] lives of employees become surrounded by negativity and other harmful consequences". Employees' deviant workplace behaviour has been described in various ways such as anti-social behaviour, counter-productive behaviour, workplace aggression, organizational incivility, and workplace misbehaviour (Appelbaum et al., 2007). By whatever name it is called, "if the behaviour is not mentioned in the formal job definition, it is beyond the existing role expectations and it violates organisational norms, such behaviour is regarded as deviant" (Yildiz, et al., 2015: 414). Two types of deviant behaviours are identified: positive deviance (in which employees honourably violate organizational norms by going beyond their 
job requirements to add value to their organizations) and negative deviance (in which employees commit acts that undesirably affect their organizations and/or co-workers) (Appelbaum et al., 2007). In this study, we are concerned with the negative dimension of deviant behaviour in the workplace. The interest in negative deviant behaviour is as a result of its undesirable consequences for organizations and their employees.

Although health workers are among the employees most involved in emotional labour (Lee and Ji, 2018), not much has been done to explore the possible negative consequences of emotional labour and deviant workplace behaviour among health workers. This study, therefore, was intended to fill these gaps. On the basis of this, the following research question is asked: how are emotional labour outcomes of superficial acting, deep acting, and honest acting related to deviant workplace behaviour? Drawing from the research question, the research aim is to determine how emotional labour outcomes of superficial acting, deep acting, and honest acting are related to deviant workplace behaviour.

The remainder of this paper is organized as follows. Section 2 focuses on reviewing the existing literature on DWB (i.e. deviant workplace behaviour), the typology of DWB, emotional labour in the workplace, and the theoretical framework. Section 3 discusses the methods and procedures employed in gathering data. Sections 4 and 5 comprise the results and discussion of the findings respectively. Finally, Section 6 contains conclusions, managerial implications, and suggestions for future research.

\section{Literature Review}

\section{Deviant Workplace Behaviour}

Generally, concerning workplace behaviour, deviance is a concept relating to several human conducts which are inconsistent with the rules, regulations, and the expected behaviour of persons within an organization (Peterson, 2002). Workplace deviance may also be seen as the deliberate or intentional desire to cause harm to an organization (Omar et al., 2011) or when employees do not conform to the policies, values, and culture of the organization, which compromises its standards, welfare, and vision (Bennett and Robinson, 2000). Warren (2003) conceptualized the construct more neutrally and simply as a departure from norms. However, it was Robinson and Bennett (1995: 556) who provided a profound definition of workplace deviance to mean "voluntary behaviour that violates significant organisational norms, and in so doing, threatens the well-being of an organisation, its members, or both”. This conceptualization was based on investigations of Robinson and Bennett (1995) and Bennett and Robinson (2000), who have been widely cited in further 
research by other scientists (Appelbaum et al., 2007). Therefore, this study adopts the construct of deviant workplace behaviour as defined by Robinson and Bennett (1995). From these definitions, particular emphasis is given to organizational norms as prescribed by formal and informal organizational policies, procedures, and rules. This is so because for any behaviour to be termed deviant, it must be defined in terms of set standards by a social group (Robinson and Bennett, 1995).

\section{The Typology of Deviant Workplace Behaviour}

Classifications of deviant workplace behaviour were long proposed by a few authors before Robinson and Bennett (1995). For example, Mangione and Quinn (1975) were those who first introduced the concepts of property deviance and production deviance, in the context of which they distinguished between serious and non-serious organizational rule breaking. The framework that was based on property deviance and production deviance was initially set up by Hollinger and Clark (1982), while Redeker (1989) published a list of punishable offences in the workplace.

However, Robinson and Bennett (1995) developed a multidimensional scaling technique to analyse the various negative deviant workplace behaviours, which vary along two dimensions: organizational deviance versus interpersonal deviance and minor versus serious deviance. Organizational deviance covers a range of negative behaviours targeted at the organization itself; interpersonal deviance is about negative behaviours that are directed at co-workers. On the other hand, the minor versus serious dimension of deviance relates to the gravity or intensity of the effect of the behaviour whether targeted at co-workers or at the organization itself. Robinson and Bennett (1995: 557) contended that the frameworks mentioned above did not organize and incorporate diverse behaviours into an expression pattern of interpersonal nature such as physical aggression and sexual harassment. The need to capture the social aspects of an organization with a history of workplace deviance was brought to the fore by Robinson and Bennett (1995), who went on to provide that in their framework: a typology of DWB, and they discussed it as follows.

Production Deviance. This refers to behaviours that go against the formerly agreed norms, defining the least quality and quantity of work to be achieved (Rogojan, 2009: 14). Behaviours that fall under production deviance include employees' absenteeism, lateness to work, leaving workplace before closing hour, spending too much time on breaks, unproductive utilization of organizational resources, and abuse of substance in the workplace (Rogojan, 2009).

Property Deviance. It covers behaviours targeted at the organization, and they are relatively more harmful (Hussain, 2015). It refers to employees destroying or misusing the property of an organization. It might be the sabotage of equipment, stealing organizational property, and so on. These acts bring direct costs to the 
organization since work cannot continue until the damaged equipment are replaced (Norsilan et al., 2014).

Political Deviance. Robinson and Bennett (1995) described it as an insignificant interpersonal deviant behaviour involving social dealings, which positions others at a disadvantage politically or personally. Robinson and Bennett (1995) observed that incivility in the workplace, nepotism, excessive gossip about colleagues, and unhealthy competition are forms of political deviance. As noted by Rogojan (2009), those who suffer from this type of behaviour tend to be dissatisfied with their jobs; they are more likely to be depressed and are subsequently more likely to resign.

Personal Aggression. Rogojan (2009) argues that personal aggression manifests in employees in the form of being hostile, unsympathetic, and antagonistic to others in the workplace. Examples include harassing others sexually, verbal and non-verbal abuse, thwarting the efforts of co-workers, and so on. Rogojan (2009) found that employees are less committed to their organization if they suffer from physical and emotional trauma caused by the aggression of a co-worker. Perpetrators might be ostracized. The full lists of Robinson and Bennett's dimensions, categories, and the associated items can be seen below (Robinson and Bennett, 1995).

\section{Emotional Labour in the Workplace}

Emotional labour has remained a subject of interest to many researchers and writers, being defined as "the effort required on the part of the individual to express organisationally required emotions, independent of the subjective feelings of the individual" (Iyayi, 2011) and "the forced emotion management in work for a wage" (Tsang, 2011: 312). Grandey (2000) noted that emotional labour usually involves enhancing, faking, or suppressing emotions to change the emotional look; and they are commonly displayed to comply with organizational rules.

Three emotional labour strategies are outlined as surface, or superficial acting, deep acting, and effective, or honest acting (Chu et al., 2012). Although these strategies are termed differently by other authors (Lazanyi, 2010; Kundu and Gaba, 2017), it is these three (superficial acting, deep acting, and honest acting) that are adopted in this study. This is because, unlike other configurations, the strategies provide a clear distinction among them, both in meaning and in expression. These strategies are discussed here.

Superficial Acting. This is a situation where employees simulate emotions that are not actually felt, by varying their external manifestations, facial expressions, voice tone, or gestures when demonstrating the necessary emotions (Chu, 2002). For example, a customer service desk staff member in the Nigerian "new generation" banks is expected to put on a smile to cheerfully receive a customer even if s/he is actually down. In this way, employees feign emotions that are not experienced. This emotional labour strategy focuses on the customer's response, and it only 
modifies the visible expressions on the surface (Kim et al., 2017) as the employees put on a façade as if the emotions were truly felt (Kumar et al., 2010). In this way, Henning-Thurau et al. (2006) contended that surface acting lacks authenticity because it only constitutes the expression of feigned emotions.

Deep Acting. Deep acting is said to be the felt emotions that seek to align expected displays with the integral experience and behaviours by regulating the expressions (Kiran and Khan, 2014). Deep acting necessitated individuals to tailor their feelings to expressing the reaction required them to exhibit. Virk and Malhotra (2016) have observed that not only does deep acting require the manifest behaviour to be suppressed, but it also expects that the inner feelings are controlled accordingly for they attempt to feel the emotions they want to display (Humphrey et al., 2008). A case in point for deep acting would be when a healthcare provider, who is indignant at a patient's disregard for instructions, suddenly works on his/her feelings to show how much s/he shares the patient's pains and hence displays a friendly gesture, just to be able to serve the patient (Pandey and Singh, 2016; Akanni and Adeniji, 2016). It has been said that because deep acting is not only about outer but inner expression, which employees evoke by recalling past joyful circumstances to create appropriate emotion, the strategy appears authentic to the audience because it requires putting one's self in another's shoes (Kim et al., 2017).

Honest Acting. Effective acting, which is a third type or strategy of emotional labour, has been seen as a situation in which one's spontaneous emotional response to a particular circumstance meets the emotional requirements of one's organization (Lazanyi, 2010). Chu (2002) asserted that the work of Hochschild (2003) ignored the situation in which employees spontaneously and genuinely experience and express the expected emotion without having to exert any effort. Kiran and Khan (2014) have said that this type of emotion is where the felt emotion aligns with the displayed emotion as well as with the one expected by the organization. Companies are no longer content with surface acting, they now seek effective acting from their employees, as the rate of competition increases, to enhance the authenticity of the service performance and reduce the possibility of breaking the display rules (Chu, 2002). As submitted by Lazanyi (2010), if the individual's genuine emotions are in agreement with what the work organization expects, neither emotional dissonance nor negative side-effects will develop.

\section{Theoretical Framework}

This study is built on the self-determination theory (SDT). The theory was developed by Edward Deci and Richard Ryan in 1970 to explain human motivation. They described motivation in this context as things that move people to act. The theory is built on a positive human tendency for growth and is facilitated by three core needs, namely: autonomy, competence, and relatedness. Self-determination promotes a 
sense of control in making choices and gets employees motivated to take actions that reflect their emotions. SDT focuses on the extent to which people's behaviour in the workplace is self-motivated and self-determined. Previous studies have discussed human behaviour factors that serve as antecedents of deviant workplace behaviours. These factors can be categorized as individual factors, organizational factors, and work-related factors.

Organizational factors. One of the key factors identified in the literature as the cause of DWB is perceived injustice among employees. Other organizational factors responsible for DWB include organizational frustration, lack of control over the work environment, weak sanctions for violation of rules, and perceived unfavourable organizational changes such as layoff. Organizational justice relates to the perception of fairness among employees in the workplace. It has been empirically established that employees' motivation and performance are determined by their perception of fairness in the organization (Setiawati and Ariani, 2020). For instance, employees that feel abused or unjustly treated have a higher tendency of engaging in deviant behaviour that is targeted towards the given organization in general and sometimes towards the offending managers or colleagues. Transparency in the ways things are done in the workplace could help in minimizing DWB. Also, respectful and constructive feedback to subordinates that feel abused and maltreated by their superiors can help to limit employees' sensitivity and negative reactions.

Individual factors. The individual factors responsible for DWB include personality traits, negative affectivity, and emotional intelligence, among others. Personality traits such as surgency have been empirically established to promote interpersonal deviance in the form of bullying and working for selfish interests (Abdullah and Marican, 2016); low agreeableness, which is the inability to get along with others, has been found to promote uncaring and unsympathetic attitudes to others; adjustment in the form of emotional instability also promotes anxiety, anger, and depression, while individuals that have low conscientiousness are prone to exhibit behaviours that are counterproductive. Unwillingness to experience change in behaviour has also been found to significantly promote employees' deviant behaviour in the workplace (Abdullah and Marican, 2016).

Work-related factors. Abusive supervision and job stress are some of the workrelated factors that can promote DWB among employees. Abusive supervision as a sustained demonstration of non-face-to-face, verbal, and non-verbal but hurtful attacks against subordinates by their supervisors (Ambrose and Ganegoda, 2020) can manifest in the form of public derogation. This kind of behaviour is capable of negatively affecting employees' health and well-being, thereby promoting DWB among them. Emotional exhaustion, depression, and anxiety are possible negative organizational outcomes of abusive supervision. In a similar vein, job stress which arises when job demands exceed employee capacity can result in behavioural outcomes such as absenteeism, smoking, abuse of substances, and so on. 
In summary, most of the studies in this area were done in the developed countries of Europe, America, and Asia. In Nigeria, while we acknowledge the recent growing interest of researchers in the phenomenon of deviance, very few studies done on the public service generally and on health institutions in particular have been documented so far.

\section{Methodology}

\section{Sample and Collection of Data}

Data were collected from health workers in two teaching hospitals (University of Benin Teaching Hospital and Irrua Specialist Teaching Hospital) in Nigeria. The choice of the samples is based on the status of the teaching hospitals in terms of the variety of the care services they render and the expected number of employees who work there. Four hundred health workers (doctors, nurses, pharmacists, laboratory scientists, medical record managers) were randomly selected from the two hospitals. The rationale for investigating health workers is that they are often expected to go out of their way in making the concerns of patients and their relatives a priority (Logan, 2016). However, this expectation appears to be unrealistic as it is observed that there is an emerging unwholesome behaviour - theft of supplies and medicines, sabotage, acting rudely, habitual lateness to work, buck-passing, and loafing, among others - among health workers in public health institutions (Olabimitan and Alausa, 2014).

Collection of data was done through the use of structured questionnaire, which was administered within four weeks. This period is similar to the time spent by De Clercq et al. (2019) on administering their instrument. Concerning information disclosure through questionnaire completion, respondents were reluctant, as expected, to freely give adequate information about their negative behaviour in the workplace. This was not so much a surprise, considering the nature of variables (emotions and negative behaviours) for the study. To mitigate these limitations, the following steps were taken: inclusion of a statement of assurance of anonymity in the data gathering instrument, the construction/adaptation of the survey questions to reflect impersonal, third-person contemplation, and collaboration with the executives of relevant workers' associations in the hospitals to reach the target respondents.

\section{Operational Definitions of Constructs}

The items are presented in terms of dependent and independent variables, as used in previous studies. 
Table 1. Operational measures

\begin{tabular}{|c|c|c|c|c|c|}
\hline $\mathbf{S} / \mathbf{N}$ & Item & $\begin{array}{l}\text { Operational Definition and } \\
\text { Source }\end{array}$ & Scale & $\begin{array}{l}\text { Number of } \\
\text { Questions }\end{array}$ & $\begin{array}{l}\text { Reliability } \\
\text { Values }\end{array}$ \\
\hline \multicolumn{6}{|c|}{ Emotional labour constructs } \\
\hline 1 & $\begin{array}{l}\text { Superficial } \\
\text { Acting }\end{array}$ & $\begin{array}{l}\text { Employees simulating } \\
\text { emotions that are not } \\
\text { actually felt, by changing } \\
\text { their outward appearances, } \\
\text { facial experience, voice tone, } \\
\text { or gestures when exhibiting } \\
\text { required emotions (Chu, } \\
\text { 2002). }\end{array}$ & $\begin{array}{l}\text { Likert- } \\
\text { type, } \\
\text { five-point } \\
\text { scale }\end{array}$ & 4 & 0.800 \\
\hline 2 & $\begin{array}{l}\text { Deep } \\
\text { Acting }\end{array}$ & $\begin{array}{l}\text { Individuals influencing } \\
\text { what they feel to express the } \\
\text { reaction or take on the role } \\
\text { they are required to play } \\
\text { (Virk and Malhotra, 2016) }\end{array}$ & $\begin{array}{l}\text { Likert- } \\
\text { type, } \\
\text { five-point } \\
\text { scale }\end{array}$ & 2 & 0.786 \\
\hline 3 & $\begin{array}{l}\text { Honest } \\
\text { acting }\end{array}$ & $\begin{array}{l}\text { Spontaneous emotional } \\
\text { response to a particular } \\
\text { circumstance meets the } \\
\text { emotional requirements of } \\
\text { the organization (Lazanyi, } \\
\text { 2010; Kiran and Khan, 2014). }\end{array}$ & $\begin{array}{l}\text { Likert- } \\
\text { type, } \\
\text { five-point } \\
\text { scale }\end{array}$ & 2 & 0.807 \\
\hline \multicolumn{6}{|c|}{ Deviant workplace behaviour dimensions } \\
\hline 4 & $\begin{array}{l}\text { Production } \\
\text { deviance }\end{array}$ & $\begin{array}{l}\text { Norm-breaking behaviour } \\
\text { directed at the organization } \\
\text { with the intention to reduce } \\
\text { work output (Robinson and } \\
\text { Bennett, 1995; Al-Fayyad, } \\
\text { 2015). }\end{array}$ & $\begin{array}{l}\text { Likert- } \\
\text { type, } \\
\text { five-point } \\
\text { scale }\end{array}$ & 5 & 0.967 \\
\hline 5 & $\begin{array}{l}\text { Property } \\
\text { deviance }\end{array}$ & $\begin{array}{l}\text { Norm-breaking behaviour } \\
\text { directed at the organization } \\
\text { and its property (Robinson } \\
\text { and Bennett, 1995; Al- } \\
\text { Fayyad, 2015). }\end{array}$ & $\begin{array}{l}\text { Likert- } \\
\text { type, } \\
\text { five-point } \\
\text { scale }\end{array}$ & 6 & 0.959 \\
\hline 6 & $\begin{array}{l}\text { Political } \\
\text { deviance }\end{array}$ & $\begin{array}{l}\text { Norm-breaking behaviour } \\
\text { directed at co-workers to } \\
\text { undermine their interests } \\
\text { (Robinson and Bennett, 1995; } \\
\text { Al-Fayyad, 2015). }\end{array}$ & $\begin{array}{l}\text { Likert- } \\
\text { type, } \\
\text { five-point } \\
\text { scale }\end{array}$ & 5 & 0.985 \\
\hline 7 & $\begin{array}{l}\text { Personal } \\
\text { aggression }\end{array}$ & $\begin{array}{l}\text { Norm-breaking behaviour } \\
\text { that harms co-workers and } \\
\text { affects their properties } \\
\text { (Robinson and Bennett, 1995; } \\
\text { Al-Fayyad, 2015). }\end{array}$ & $\begin{array}{l}\text { Likert- } \\
\text { type, } \\
\text { five-point } \\
\text { scale }\end{array}$ & 6 & 0.948 \\
\hline
\end{tabular}




\section{Estimation Techniques}

Descriptive statistics, such as frequency distribution and mean, were used to describe the demographic attributes of the respondents, while bivariate analysis using correlation coefficient was used to estimate the relationship between emotional labour and deviant workplace behaviour (Bechtoldt et al., 2007; Hwa and Amin, 2016). Data obtained were compressed accordingly. Four instances, four items or questions were used to measure superficial acting. The average of the responses to the four items was taken to form a single column to represent the variable which is used in conducting the bivariate analysis. The same procedure was implemented for other constructs or variables.

\section{Results}

Out of the four hundred (400) copies of the questionnaire administered to health workers (doctors, nurses, pharmacists, laboratory scientists, medical record managers) in the two hospitals, 327 copies were found to be valid and usable.

\section{Respondents’ Demographic Characteristics}

Results show that 110 (33.6\%) of the respondents were male, while 217 (66.4\%) were female. This shows that most of the health workers examined were female. The age distribution showed that the majority of the respondents $(131,40.1 \%)$ were between 26 and 35 years old. This is followed by respondents within the age range of $36-45$ years. This category accounts for $28.4 \%$. Some 60 (18.3\%) of the respondents were 25 years old or less. Only $13.1 \%$ of the respondents were between 46 and 55 years. The respondents' work experience in the health sector shows that $134(41 \%)$ of the respondents have worked five years or less. 126 $(38.5 \%)$ of the respondents have worked between six and ten years, while 39 $(11.9 \%)$ of them have worked between eleven and fifteen years. Only $28(8.6 \%)$ of the respondents have worked for sixteen years or more. The age range of most of the respondents is between 26 and 45 years, while the average years of respondents' work experience are between 6 and 10. This shows that the majority of the respondents are experienced. It can be asserted that the respondents who filled in the questionnaire were knowledgeable in the activities of teaching hospitals. 


\section{Descriptive Statistics and Correlation Analyses}

Mean, standard deviation, and Pearson correlation coefficients were computed on the data for all the variables in the study. The results are shown in Table 2.

Table 2. Mean, standard deviation, and Pearson's correlation coefficients

\begin{tabular}{llllllll}
\hline Variables & SUA & DEA & HOA & PRD & PRO & POL & PER \\
\hline $\begin{array}{l}\text { Superficial } \\
\text { Acting (SUA) }\end{array}$ & 1 & & & & & & \\
\hline $\begin{array}{l}\text { Deep Acting } \\
\text { (DEA) }\end{array}$ & $0.554^{* *}$ & 1 & & & & \\
\hline $\begin{array}{l}\text { Honest acting } \\
\text { (HOA) }\end{array}$ & 0.046 & $0.270^{* *}$ & 1 & & & & \\
\hline $\begin{array}{l}\text { Production } \\
\text { Deviance (PRD) }\end{array}$ & $0.151^{* *}$ & $0.109^{*}$ & $-0.154^{* *}$ & 1 & & & \\
\hline $\begin{array}{l}\text { Property } \\
\text { Deviance (PRO) }\end{array}$ & $0.259^{* *}$ & $0.154^{* *}$ & $-0.113^{*}$ & $0.629^{* *}$ & 1 & & \\
\hline $\begin{array}{l}\text { Political } \\
\text { Deviance (POL) }\end{array}$ & $0.217^{* *}$ & $0.297^{* *}$ & $-0.159^{* *}$ & $0.551^{* *}$ & $0.571^{* *}$ & 1 & \\
\hline $\begin{array}{l}\text { Personal } \\
\text { Aggression (PER) }\end{array}$ & $0.398^{* *}$ & $0.334^{* *}$ & -0.083 & $0.300^{* *}$ & $0.428^{* *}$ & $0.586^{* *}$ & 1 \\
\hline Mean & 2.587 & 3.569 & 4.384 & 2.983 & 2.749 & 3.24 & 3.071 \\
\hline $\begin{array}{l}\text { Standard } \\
\text { Deviation }\end{array}$ & 1.016 & 1.087 & 0.713 & 0.917 & 0.962 & 0.675 & 1.006 \\
\hline Note: $N=327 *^{*}=P<5 \% *^{* *}=p<1 \%$ & & & & & \\
\hline
\end{tabular}

Note: $N=327,{ }^{*}=P<5 \% ;{ }^{*}=p<1 \%$

Table 2 shows the Pearson's correlation coefficients between each pair of variables. Bryman and Cramer (1997) posit that "the Pearson's correlation coefficient (r) should not exceed 0.80; otherwise the independent variables that show a relationship above 0.80 may be suspected of having multi-collinearity". The results in Table 2 show that none of the correlation coefficients reaches 0.80 ; hence, it can be inferred that multicollinearity is not present in the model. Table 2 shows that surface acting and deep acting are positively and significantly related to all the four dimensions of deviant workplace behaviour. However, effective acting has a negative but significant relationship with all the four dimensions of deviant workplace behaviour.

\section{Discussion of Findings}

The study found that superficial acting and deep acting have a positive relationship with property deviance among health workers, whereas honest acting was found to have negative relationship with property deviance among them. These results are 
generally consistent with several previous related studies. For instance, Alias et al. (2013) found that when employees are emotionally strained due to the management of observable expressions, they become more susceptible to developing negative behaviours. In the same way, Grandey (2000) observed that in service performance superficial acting would negatively impact customer service. Faked emotions, or superficial acting seems to have a "leakage" through which observers can detect the deception. As suggested by Hochschild (2003), the job demand for superficial acting brings about stressful experiences for the employee. Generally, individuals would not want to feel fake, and the suppression of true emotions to express fake emotions requires a great deal of effort with its attendant negative outcomes, chiefly engaging in deviant workplace behaviour such as aggression towards co-workers and patients in the case of health institutions. Moreover, Morris and Feldman (1996) found a link between the suppression of the emotion acted superficially and a variety of deviant workplace behaviours such as drug use, alcohol abuse, and absenteeism.

However, the finding slightly differs from that of Chu (2002), who revealed that the consequences of emotional labour were both positive and negative. It is positive if performed well to bring about customer satisfaction, customer loyalty, and the eventual organizational performance. The negative outcome of superficial acting, apart from its toll on the health conditions of the "actors", includes financial losses, sabotage, and aggression, among others. Most times, publicly owned institutions, such as the teaching hospitals, are less rigid in their application of rules and regulations, and most importantly they are not established primarily for profit maximization.

A significant and positive relationship was found between deep acting and deviant workplace behaviour (political deviance and personal aggression). This confirms some previous findings (Fox and Spector, 1999; Lee and Ok, 2014), which indicated that the emotional labour of deep acting was positively associated with service sabotage as employees who work hard to feel the emotions they are expected to express are likely to engage in deviant behaviours. This is because the constant emotional consumption in the course of the "labour" is a drain on their psychological and emotional energy. The emotionally depleted employees are most likely to reduce or withhold personal involvement, and this depersonalization of service is likely to make them frustrated and then prompt them to engage in service misbehaviours to compensate for the loss in personal resourcefulness, as explained by the conservation of resources theory (Ahmed and Omar, 2013). By the same token, in a related study that investigated nurses' burnout and counterproductive work behaviour in a Nigerian sample, Ugwu et al. (2017) found that burnout not only positively but also significantly predicted counterproductive work behaviour. These findings are also consistent with those of Kiran and Khan (2014) that deep acting results in stress and job burnout leading to all kinds of workplace 
misbehaviour and with that of Grandey (2000) that emotion management of deep acting enhances the individual's physiological arousal, which in turn may force employees to withdraw from work, and that individuals with negative emotions will be more affected by workplace stressors and will more likely be involved in emotional labour and engaged in deviant behaviours.

Another important finding concerns the relationship between honest acting and deviance. Not surprisingly, our finding shows a negative relationship between honest acting and all deviant workplace behaviour constructs. First, it should be noted that honest acting is the expression of genuine emotions, in which one's spontaneous emotional response to a particular situation meets the emotional requirements of his/her organization. The finding here corroborates Chu's (2002) that since genuineness is a product of fusing the private self and the public self, employees usually invest their true selves in their jobs. As they have good interactions with customers, the genuineness of their emotions would lead to positive job outcomes. This is also in line with Hochschild's (2003) observation that service employees who tend to genuinely enact emotional labour usually meet customers' and organizations' expectations.

We can be certain that this finding, apart from confirming previous results, fulfils any common sense condition. The employee who honestly displays felt emotions towards customers would naturally not engage in any form of misbehaviour to hurt either customers or the organization. On many occasions, personal experiences and those of others show that health workers frequently empathize with patients genuinely. What normally follows is a very caring and concerned show through service delivery. This genuineness excludes any form of deviation targeted either at the individual or at the organization.

\section{Conclusions and Recommendations}

This study has shown that health workers, in their bid to provide the needed services to patients, are involved in emotion management, called emotional labour, on a daily basis through the various strategies of superficial acting, deep acting, and honest acting. The study has further shown that deviant workplace behaviours among health workers in teaching hospitals are pervasive and are in response to organizationally accepted ways of emotional expressions. Drawing from the findings, it is concluded that a clear relationship exists between emotion management and deviant workplace behaviour among health workers in teaching hospitals. It also shows that organizations in Nigeria (service organizations in particular) are faced with deviant workplace behaviour, majorly as a consequence of "working" to produce and display organizationally required emotions while relating to customers. 


\section{Managerial Implications}

Practically, the value of this study is that researchers and practitioners in the field of organizational behaviour are provided with information relating to emotional labour and deviant workplace behaviour in organizations generally and in health institutions in particular, rather than depend on perception. On the other hand, it provides government, managers of health institutions, and other policy-makers with the necessary information for the formulation of tailor-made policies for the management of all kinds of negative deviant behaviours arising from employees' emotion management in health institutions.

The management of teaching hospitals as well as government organizations should ensure that rules and policies are enforced to curb certain deviant behaviours, which are rapidly becoming norms if taken for granted.

There is a need to achieve a person-job fit for health workers of all categories. To achieve this, health workers in training should be exposed to the reality that they would be required to master their emotions in order to succeed in their practice. In doing this, authorities of various institutions - backed by government policy - where health workers are trained should include emotion management in their training manual as well as provide counselling to address emotional burden borne by employees in order to reduce incidences of DWB.

\section{Research Limitations and Suggestions for Future Studies}

The limitations of this study were the chosen scope of the study and respondents' level of willingness to disclose information. Although the study was concerned with deviant workplace behaviour among health workers in teaching hospitals, only health workers in the two government-owned teaching hospitals in Edo State, Nigeria, were included in the study, based on which generalized conclusions are reported. It is therefore noted that the scope of future studies on the subject matter should be expanded to include other health institutions, other than teaching hospitals, and should cover other parts of the country as well. Secondly, the health implications of emotional labour for the "actors" were not part of the study scope. Other researches in the future should look at the psychological and physiological effects of emotional labour on the employees involved. 


\section{References}

Abdullah, A.; Marican, S. (2016). The effects of big-five personality traits on deviant behavior. Procedia - Social and Behavioral Sciences 219: 19-25.

Ahmad, A.; Omar, Z. (2013). Abusive supervision and deviant workplace behaviour: The mediating role of work-family conflict. The Journal of Human Resource and Adult Learning 9(2): 124-130.

Akanni, A. A; Adeniji, O. G. (2016). Personality traits and emotional labour of nurses in Osun State, Nigeria. British Journal of Arts and Social Sciences 21(1): 72-82.

Al-Fayyad, M. (2015). Validating typology of Robinson and Bennett of deviant workplace behaviour (DWB) in Jordanian industrial sector in Zarqa City. Journal of Business Studies Quarterly 5(4): 31-45.

Alias, M.; MohdRasdi, R.; Ismail, M.; Abu S. B. (2013). Predictors of workplace deviant behaviour: HRD agenda for Malaysian support personnel. European Journal of Training and Development 37(2): 161-182.

Ambrose, M. L; Ganegoda, D. B. (2020). Abusive according to whom? Manager and subordinate perceptions of abusive supervision and supervisors' performance. Journal of Organizational Behavior 41(8): 737-756.

Appelbaum, S. H.; Iaconi, G. D; Matousek, A. (2007). Positive and negative deviant workplace behaviours: Causes, impacts, and solutions. Corporate Governance 7(5): 586-598.

Bechtoldt, M. N.; Welk, C.; Zapf, D.; Hartig, J. (2007). Main and moderating effects of self-control, organizational justice, and emotional labour on counterproductive behaviour at work. European Journal of Work and Organizational Psychology 16(4): 479-500.

Bennett, R. J.; Robinson, S. L. (2000). The development of a measure of workplace deviance. Journal of Applied Psychology 85(3): 349-360.

Bryman, A.; Cramer, D. (1997). Quantitative data analysis with SPSS for Windows: A guide for social scientists. Routledge.

Chu, K. H. (2002). The effects of emotional labour on employee work outcomes. An unpublished doctoral dissertation submitted to the Faculty of the Virginia Polytechnic Institute and State University, Blacksburg, Virginia.

Chu, K. H.; Baker, M. A.; Murrmann, S. K. (2012). When we are onstage, we smile: The effects of emotional labor on employee work outcomes. International Journal of Hospitality Management 31(3): 906-915.

De Clercq, D.; Haq, I. U.; Azeem, M. U. (2019). Perceived contract violation and job satisfaction. International Journal of Organizational Analysis 28(8): 383-397.

Fox, S.; Spector, P. E. (1999). A model of work frustration-aggression. Journal of Organisational Behaviour 20(6): 915-931. 
Grandey, A. A. (2000). Emotional regulation in the workplace: A new way to conceptualize emotional labor. Journal of Occupational Health Psychology 5(1): 95-108.

Hennig-Thurau, T.; Groth, M.; Paul, M.; Gremler, D. D. (2006). Are all smiles created equal? How emotional contagion and emotional labor affect service relationships. Journal of Marketing 70(3): 58-73.

Hochschild, A. R. (2003). The managed heart: Commercialization of human feeling. Twentieth Anniversary Edition. Berkeley and Los Angeles: University of California Press.

Hollinger, R. C.; Clark, J. P. (1982). Formal and informal social controls of employee deviance. The Sociological Quarterly 23(3): 333-343.

Humphrey, R. H.; Pollack, J. M.; Hawver, T. 2008. Leading with emotional labor. Journal of Managerial Psychology 23(2): 151-168.

Hussain, I. (2015). Deviant workplace behaviour: Examining the role of some antecedents and moderators. Unpublished doctoral thesis. Pondicherry University, Pondicherry.

Hwa, M. A. C.; Amin, H. (2016). Why emotion at work matters: Examining the influence of emotional labour and emotional intelligence on workplace behaviours among service workers in east Malaysia. Kajian Malaysia 34(1): 79-105.

Iyayi, F. (2011). Behaviour and emotions. Unpublished M.Sc. lecture notes at the Faculty of Management Sciences, University of Benin, Benin City.

Kim, H. J.; Hur, W.; Moon, T.; Jun, J. (2017). Is all support equal? The moderating effects of supervisor, coworker, and organisational support on the link between emotional labour and job performance. Business Research Quarterly 20: 124-136.

Kiran, A.; Khan, M. A. (2014). Perceived organisational support and emotional labour: The mediating role of emotional intelligence. Research Journal of Recent Sciences 3(10): 1-11.

Kumar, S.; Shankar, B.; Singh, A. P. (2010). Emotional labour and health outcomes: An overview of literature and preliminary empirical evidences. Indian Journal of Social Science Researches 7(1): 83-89.

Kundu, S. C; Gaba, N. (2017). Emotional dissonance and organisational deviance: The mediating role of intention to quit. International Journal of Applied Business and Economic Research 15(4): 485-499.

Lazanyi, K. (2010). Emotional labour and its consequences in health-care setting. In: Proceedings of FIKUSZ'10 Symposium for Young Researchers, Budapest, Hungary. 149-156.

Lee, E. K.; Ji, E. J. (2018). The moderating role of leader-member exchange in the relationships between emotional labour and burnout in clinical nurses. Asian Nursing Research: 1-6. 
Lee, J.; Ok, C. M. (2014). Understanding hotel employees' sabotage: Emotional labour perspective based on conservation of resources theory. International Journal of Hospitality Management 36: 176-187.

Logan, T. R. (2016). Influence of teamwork behaviours on workplace incivility as it applies to nurses. Creighton Journal of Interdisciplinary Leadership 2(1): 47-53.

Mangione, T. W.; Quinn, R. P. (1975). Job satisfaction, counter-productive behaviour, and drug use at work. Journal of Applied Psychology 60(1): 114-116.

Morris, J. A.; Feldman, D. C. (1996). The dimensions, antecedents, and consequences of emotional labor. Academy of Management Review 21(4): 986-1010.

Norsilan, I. N.; Omar, Z.; Ahmad, A. (2014). Workplace deviant behaviour: Does employee psychological job demand and lack of job resources influence employee workplace deviant behaviour? Journal of Malaysian Psychology 28(2): 39-62.

Olabimitan, B; Alausa, W. M. (2014). Psychological factors predicting workplace deviance behaviour among nurses in the public health sector in Lagos. Nigerian Journal of Applied Behavioural Sciences 2(June): 137-152.

Omar, F.; Halim, F.; Zainah, A.; Farhadi, H. (2011). Stress and job satisfaction as antecedents of workplace deviant behaviour. World Applied Science Journal 12(Special Issue of Social and Psychological Sciences for Human Development): $46-51$.

Pandey, J.; Singh, M. (2016). Donning the mask: Effects of emotional labour strategies on burnout and job satisfaction in community healthcare. Health Policy and Planning 31: 551-562.

Peterson, D. K. (2002). Deviant workplace behaviour and the organisation's ethical climate. Journal of Business and Psychology 17(1): 47-61.

Redeker, J. R. (1989). Employee discipline: Policies and practices. Washington, DC: Bureau of National Affairs.

Robinson, S. L.; Bennett, R. J. (1995). A typology of deviant workplace behaviours: A multidimensional scaling study. Academy of Management Journal 38(2): $555-572$.

Rogojan, P. (2009). Deviant workplace behaviour in organisations: Antecedents, influences, and remedies. Unpublished diploma thesis. University of Vienna.

Setiawati, T.; Ariani, I. D. (2020). Influence of performance appraisal fairness and job satisfaction through commitment on job performance. Review of Integrative Business and Economics Research 9(3): 133-151.

Tsang, K. K. (2011). Emotional labour of teaching. Emotional Research 2(8): 13121316.

Ugwu, L. I.; Enwereuzor, I. K.; Fimber, U. S.; Ugwu, D. I. (2017). Nurses’ burnout and counter-productive work behaviour in a Nigerian sample: The moderating role of emotional intelligence. International Journal of Africa Nursing Sciences 7: 106-113. 
Virk, A. G.; Malhotra, M. (2016). 'Manufacturing emotion': A study of the emotion work performed and burnout experienced by managers from a few selected manufacturing companies in India. International Journal of Scientific and Research Publications 6(6): 162-171.

Warren, D. E. (2003). Constructive and destructive deviance in organisations. Academy of Management Review 28(4): 622-632.

Yildiz, B.; Alpkan, L.; Sezen, B.; Yildiz, H. (2015). A proposed conceptual model of destructive deviance: The mediator role of moral disengagement. $11^{\text {th }}$ International Strategic Management Conference. Procedia - Social and Behavioural Sciences 207: 414-423. 